\title{
HOMENS QUE DANÇAM: SEXUALIDADES E ENVELHECIMEN- TO NA CENA E NA DOCÊNCIA CONTEMPORÂNEA
}

\section{MEN WHO DANCE: SEXUALITIES AND AGING IN THE SCENE AND IN CONTEMPORARY TEACHING}

\author{
DOI: http://dx.doi.org/10.5965/1984317815032019106
}

\author{
Gustavo de Oliveira Duarte \\ Universidade Federal de Santa Maria \\ guto.esef@gmail.com
}

\begin{abstract}
RESUMO
O texto trata de uma pesquisa realizada em Salvador/BA, vinculada ao Programa de Pós-graduação em Dança que investigou homens que dançam e suas interfaces com a vivência da sexualidade e com o processo do envelhecer. A pesquisa de campo se deu em três contextos: cena, docência e artistas independentes. Os primeiros eixos contemplaram bailarinos do Balé do Teatro Castro Alves (BTCA) e da Escola de Dança da Fundação Cultural do Estado da Bahia (FUNCEB). Foram realizadas entrevistas semi-estruturadas com os artistas e algumas aulas e ensaios foram observadas e registradas em um diário de campo. O preconceito da família, o privilégio e a autonomia de ser homem, a ressignificação do corpo e da dramaturgia da dança, além de projetos para o futuro foram alguns achados mais significativos. O contexto de Salvador que permite uma rica vivência da dança e o seu aprofundamento acadêmico contribuíram significativamente para a formação dos artistas da dança e sua independência profissional.
\end{abstract}

Palavras-chave: Homens. Sexualidade. Envelhecimento. Gênero. Docência.

\begin{abstract}
The text is a research done in Salvador / BA, linked to the Postgraduate Program in Dance, with men who dance and their interfaces with the experience of sexuality and with the process of aging. The field research took place in three contexts: scene, teaching and independent artists. The first axes included ballet dancers from the Castro Alves Theater (BTCA) and dancers from the Dance School of the Cultural Foundation of the State of Bahia (FUNCEB). Semi-structured interviews were conducted with the artists and some classes and essays were observed and registered in a field diary. The preconception of the family, the privilege and autonomy of being a man, the resignification of the body and the dramaturgy of dance, as well as projects for the future were some of the most significant findings. The context of Salvador, which allows a rich experience of dance and its academic deepening, contributed significantly to the constitution of dance artists and their professional independence.
\end{abstract}

Keywords: Men. Sexuality. Aging. Gender. Teaching. 


\section{INTRODUÇÃO}

Este artigo trata de uma pesquisa de Pós-doutoramento realizada na Escola de Dança da Universidade Federal da Bahia (UFBA) a partir da temática das relações de Gênero e Sexualidade, sobretudo das Masculinidades, e sua interface com o processo do envelhecimento. Os dois principais eixos de investigação e análise foram o contexto da cena artística e o contexto da docência de artistas homens ligado à Dança. Especificamente no Brasil compreendemos que a História da Dança tanto em relação a maioria de seus personagens marcantes quanto ao público que se interessou por seu estudo ou prática foi marcada, em grande parte, pelo público feminino. Com o objetivo de superar tradicionais dicotomias e desconstruir padrões e estereótipos de gênero, como também visibilizar e problematizar a presença e as contribuições dos homens na área da dança, esta pesquisa se orienta.

A partir de uma nova política governamental de maior apoio e expansão das Universidades públicas brasileiras, com a criação do REUNI (Reestruturação e Expansão das Universidades Federais), iniciado no ano de 2007 pelo governo federal, inúmeros Cursos de Graduação em Dança foram criados no país de modo a aumentar a visibilidade da área da Dança, seja nas Artes ou na Educação Física (Bacharelado e Licenciatura). Além disso, um fenômeno crescente das Danças, performances e intervenções urbanas e das Danças de Salão, onde a figura masculina goza de maior destaque, ajudaram a despertar um maior interesse dos homens à Dança (DUARTE, 2016).

Ao relacionar questões entre as temáticas acerca dos estudos de Gênero e Sexualidade ao processo do envelhecimento, atravessadas à área da Dança, busco investigar as transformações ao longo do tempo, de bailarinos homens, nos contextos específicos da cena e da docência. O caminho metodológico foi contextualizado a partir dos seguintes recortes: experiência e formação em dança; cena e docência; masculinidades e a dança e o processo do envelhecer no dançar. Cada artista da dança respondeu questões abertas 
sobre as temáticas da pesquisa em uma entrevista que foi gravada e posteriormente transcrita. Algumas aulas de dança dos professores e alguns ensaios e espetáculos dos bailarinos também foram analisados, bem como o conteúdo de páginas, sites e fotos oficiais dos colaboradores envolvidos e as respectivas divulgações de suas aulas e espetáculos.

Este texto também se apoia na noção de pedagogias culturais, pedagogias do gênero e da sexualidade, e entende o processo de envelhecimento como um aprendizado, complexo e contingencial. A escrita e o processo de pesquisa e produção deste artigo estão ancorados, principalmente, nas teorizações e na trajetória de Michel Foucault, sobretudo na última fase de seus estudos. Portanto, cabe destacar que meu caminho investigativo, como professor-pesquisador, se desenvolve na área da Educação e que busco problematizar e contextualizar categorias como pedagogias do gênero e da sexualidade. Neste sentido compreendo os sujeitos a partir de identidades múltiplas, plurais, não fixas e, portanto, que podem se transformar e até mesmo mostrarse contraditórias (LOURO, 1999). A orientação deste cenário epistemológico privilegia a centralidade da linguagem a partir da produção das relações que a cultura pode estabelecer entre corpo, sujeito, conhecimento e poder.

O corpo, neste sentido, é compreendido como um construto sociocultural e linguístico, produto e efeito de relações de poder (MEYER, 2003), ou seja, o corpo também é construído pela linguagem. Nesta perspectiva a cultura é caracterizada com um campo de luta e de contestação na qual são produzidos múltiplos sentidos de masculinidade e feminilidade a partir de suas "marcas" sociais tais como classe, etnia, geração, religião, nacionalidade, entre outras. A perspectiva dos Estudos Culturais, Estudos Gays e Lésbicos, estudos da Gerontologia e da Teoria Queer fundamentaram a pesquisa.

\section{GÊNERO E SEXUALIDADE(S) NO DANÇAR}

Hegemonicamente, uma série de comportamentos e expectativas sociais bem como atividades relacionadas ao espaço privado, o cuidado às crianças e 
à educação, atividades como a Ginástica e a Dança, por exemplo, foram direcionadas às mulheres para Ihe conferirem graça, beleza e harmonia (GOELLNER, 2003). A generificação de atividades e modelos sociais influenciaram decisivamente e acabou ajudando a construir a História da Educação e da Ciência (LOURO, 1998; CHASSOT, 2003) e, obviamente, interferindo nos modos de ser e de estar de sujeitos sociais por meio de relações, silenciamentos, negações, disputas.

Compreendo que a categoria de Gênero, a partir de uma visão construcionista do social, configura-se como uma ferramenta analítica e, ao mesmo tempo, política, uma vez que articulada à(s) sexualidade(s) e a outros marcadores culturais acaba funcionando como um organizador cultural e destacando o caráter relacional das práticas sociais. Ao pesquisar na interface e nas articulações entre Educação, Gênero e (homo)sexualidade(s) percebo que os estudos de gênero são capazes de (des)construir a percepção e a organização concreta e simbólica das relações sociais.

O Gênero, então, fornece um meio de decodificar o significado e de compreender as complexas conexões entre as várias formas de interação humana. Quando os/as historiadores/as buscam encontrar as maneiras pelas quais o conceito de gênero legitima e constrói as relações sociais, eles/elas começam a compreender a natureza recíproca do gênero e da sociedade e as formas particulares e contextualmente específicas pelas quais a política constrói o gênero e o gênero constrói a política (SCOTT, 1995, p. 89).

Assim, portanto, concordo que as identidades de gênero e sexuais são produzidas na e pela cultura e mostram-se permeadas por complexas relações de poder em diferentes articulações e instâncias sociais. As identidades, portanto, são nomeadas a partir de diferentes classificações como normais, desviantes, marginais, e/ou alternativas, no entanto, cabe destacar que algumas identidades não necessitam ou precisam de explicação, enquanto outras, não podem ou não devem falar por si (LOURO, 1998). 
Destaco a cultura como um campo de relações de poder. O poder de representar o outro, de se autorrepresentar, de estabelecer conexões positivas a partir de sua identidade, o poder de se apresentar como confiável, como digno, e não ser visto como um ser abjeto. Neste campo de negociações, podemos perceber que as construções culturais e as representações sociais são constituídas em meio a disputas de poder, ou seja, elas estão imersas em redes de poder em diversos campos e lugares sociais. Desse modo, a sexualidade não se constitui apenas como uma questão pessoal, mas configura-se no âmbito social e político na medida em que ela é aprendida, é construída ao longo da vida, de muitos modos e por diferentes atravessamentos. Ao relacionarmos as compreensões de corpo e de sexualidade faz-se necessário articular os conceitos de identidades, práticas sexuais e de gênero. As diferentes formas de viver e desfrutar prazeres e desejos contribuíram para a construção dos chamados processos de afirmação e diferenciação, conforme Stuart Hall (2000), denominado de políticas de identidade.

A organização e a visibilidade dos movimentos sociais de contestação, sobretudo a partir da década de 1960 e 1970, como o Movimento Feminista e o Movimento Negro, dentro e fora do país, acabou impulsionando a constituição e o fortalecimento do movimento de gays e lésbicas e de suas lutas pela livre expressão sexual e pelo reconhecimento de direitos sociais. Tais transformações sociais repercutiram em novos arranjos, novas combinações de posturas e de saberes sobre as identidades e práticas sexuais e de gênero, ou seja, aprendemos que a vivência de prazeres e de desejos pode-se dar de várias e diversas formas e não, a partir da exclusividade de uma única norma, lei ou imposição. No entanto, é válido destacar, como apontou Michel Foucault, que na norma todos estamos, mas que podemos estar em uma relação de oposição a ela, em oposição parcial, em negociação, em total adesão, entre outras possibilidades contingenciais e históricas possíveis.

A crescente organização e militância LGBT (Lésbicas, Gays, Bissexuais, Travestis e Transexuais) além de questionar a norma heterossexual e de certa forma, empoderar a visibilidade e a questão do "assumir-se gay", também 
acabou ditando um modelo mais aceito e "politicamente correto" do gay masculino, ou seja, de proximidade ao modelo heterossexual hegemônico como casar, ter filhos, viver uma vida como "todo mundo". Em relação a isso também não há um consenso no meio gay, especialmente o masculino. Ser ou estar gay também pode exigir caminhos outros de desejos e experimentações sexuais e afetivas, localizadas, contingenciais, geográficas. (SEFFNER, 2011).

É notável, no entanto, como a visibilidade gay tem incomodado a sociedade na busca de seus direitos mais ou menos "comportados". Índices de violência e homofobia estampam, constantemente, as estatísticas em grandes e pequenos centros urbanos. Esses corpos ainda importam? Para quem? A precariedade dessas vidas incomodam as políticas públicas até que ponto? Em que medida é possível viver em liberdade, à luz do dia, esses corpos desviantes, dissidentes? (BUTLER, 2016).

Mais recentemente no Brasil a chamada Teoria Queer além de apontar os limites das políticas identitárias se propõe transformar as inúmeras experiências de humilhação e sofrimento em força política de resistência e transgressão, em uma verdadeira revolução social. Um apelo, um chamado, uma dobra, uma possibilidade outra de reinvenção e resistência, sobretudo política.

(...) a proposta política queer não aponta para nenhuma divisão, antes é um apelo unificador à experiência comum de gays, lésbicas, bissexuais, travestis, transexuais e outr@s, ou seja, a experiência da vergonha. Ser chamado, leia-se, ser xingado de bicha, gay, sapatão, travesti, anormal ou degenerad@ é a experiência fundadora da descoberta da homossexualidade ou do que nome nossa sociedade atribui a ela, o espaço da humilhação e do sofrimento. Transformar esta experiência em força política de resistência é o objetivo da proposta original queer (MISKOLCI, 2010, p. 10).

A força e a potência da concepção queer concentra-se, justamente, na manifestação da diferença que não quer ser tolerada nem assimilada. Queer está, portanto, em desacordo com o normal, com a norma, seja ela da heterossexualidade, seja dos estudos gays e lésbicos (SPARGO, 2017). A novidade da Teoria Queer caracteriza-se justamente pela tentativa de sair da oposição 
binária e desigual entre homossexual e heterossexual. Caminhos outros podem mostrar-se possíveis e produtivos.

Quando jovens meninos começam a dançar e a conviver no mundo da dança muito provavelmente enfrentarão um duplo preconceito: dentro da própria família e no contexto social (DUARTE, 2016). As expectativas e normas de gênero e, sobretudo, de sexualidade, são muito altas em relação ao mundo masculino padrão, conservador, especialmente a cobrança para se tornar um "homem de verdade". Abaixo, seguem relatos de dois professores de Dança em relação às cobranças da família, enfrentamentos sociais e superação de paradigmas cristalizados culturalmente.

No início a família cobra uma postura, enquanto homem como você vai sustentar sua família, ser dançarino? Ser homem ajuda em nome dessa autonomia que você tem no mundo, você sozinho se basta, você coloca uma mochila e viaja. Mulher é mais complicado, da família, o perigo do assédio e da violência. Homem tem mais privilégios, tem mais condição de permanecer, mulher tem que cuidar da família e dos filhos, o homem não (D. 52 anos).

No sentido social é muito desafiador, mas eu tenho fibra muito forte, mas meus colegas devem ter sofrido muito, eu enfrentei algumas violências físicas e simbólicas (C. 40 anos).

No rico, multifacetado e alegre contexto de Salvador compreendi que a vivência e o exercício da sexualidade apresentam-se de certa maneira fluída, potente e muito presente na vida dos bailarinos investigados. Muitos deles iniciaram relacionamento com mulheres, alguns casaram, tiveram filhos e ainda assim transitaram em espaços homoeróticos e também se relacionaram com homens. O "meio" da dança, como eles relataram, de certa forma contribuiu significativamente para as experimentações sexuais entre homens e para a superação de preconceitos. A maioria deles afirmou que a dança favoreceu uma ampliação do olhar e de uma visão crítica acerca da vida, mais aberta, democrática e plural. No decorrer da pesquisa compreendi que para eles, o ser ou estar bissexual não é uma condição inferior ou vergonhosa e, sim, uma 
condição bastante recorrente e até mesmo positivada, respeitada de certo modo, uma espécie de trânsito.

Sou um vampiro, sempre me relaciono com homem e mulher, transpassa, vou dizer que é bi sim. Não tenho aversão de nenhum conceito. Andrógino? Híbrido? (P.F. 56 anos).

Comecei minha vida hétero, depois experimentei a bissexualidade, casei, tenho uma filha, de 20 anos, depois a relação não rolava, e hoje eu tenho uma relação gay estável, eu me sinto bem (M.N. 53 anos).

Um paradoxo deve e merece ser problematizado. Por um lado, o homem na dança é valorizado pela sua presença, pelas possibilidades de atuar em diferentes personagens, pela autonomia social e vigor físico; por outro, a suspeita e/ou confirmação de sua homossexualidade acaba lhe colocando em um lugar inferior, de desconfiança, de abjeção mesmo. Uma hierarquia se estabelece. Um rótulo é inaugurado. A fronteira, e o "estar entre" passa a incomodar.

Eu sou muito discriminado, ainda todos os dias, pela expectativa do lugar do ser professor. Não sofro tanto por ser negro, mas por ser gay, pela aparência frágil, eu percebo. Nossa, os seguranças me barravam na porta, mesmo quando eu era diretor. Você sente aquele olhar, existe até hoje (S. 47 anos).

Tem dias que eu sou mais gay, e tem dias que eu sou menos gay. Depende do meu estado de espírito, tem dias que eu visto saia, outros saio mais boyzinho. A única coisa que penso é em relação ao lugar que eu vou, se existe a possibilidade de uma violência e como eu vou atuar ali, não é se ocultar, mas depende, dependo do lugar você tem outra atitude, tanto mais afirmativa ou mais discreta. Aqui em Salvador varia muito de lugar, depende dos bairros, varia muito (L. 37 anos).

Infelizmente, ainda é recorrente nos meios de comunicação brasileiros e como alguns estudos e pesquisas chamam a atenção e denunciam os inúmeros casos e situações de agressão, perseguições, violência explícita e gratuita a uma considerável parcela de homossexuais, estejam eles mais ou menos visíveis. Seja na própria família, na escola, entre vizinhos ou descon- 
hecidos a aversão a homossexuais se direciona não apenas àqueles que se mostram mais afeminados, de "fácil identificação" - seja por uma expressão e/ ou visualidade diferenciada da masculinidade hegemônica, seja por manifestações de afeto entre homens - mas também àqueles que se parecem e/ou são confundidos com eles. Insultos, ofensas e ameaças fizeram e ainda fazem parte, de diferentes formas, da experiência social de gays, lésbicas, bissexuais, travestis e transexuais no Brasil.

Para Daniel Borrillo, pesquisador argentino radicado na França, o conceito de homofobia se refere à:

(...) hostilidade geral, psicológica e social àqueles ou àquelas que supostamente sentem desejo ou têm relações sexuais com indivíduos de seu próprio sexo. Forma particular de sexismo, a homofobia renega todos aqueles que não se enquadram nos papéis determinados para seu sexo biológico. Construção ideológica que consiste na promoção constante de uma forma (hetero) em detrimento de outra (homo), a homofobia organiza uma hierarquização das sexualidades, o que tem consequências políticas (BORRILLO, 2009, p.28).

A homofobia, segundo Borrillo, denota sentimentos de repulsa, aversão e de inferiorização a pessoas que possuem e/ou expressam desejo por outras do mesmo sexo. O autor destaca que o processo de naturalização da homofobia foi construído socialmente com forte apelo do Cristianismo, herdeiro da tradição judaica, onde a heterossexualidade foi considerada natural e dentro da normalidade diante da imagem de Deus.

De acordo com pesquisas realizadas em Paradas de Orgulho LGBT no Rio de Janeiro, Porto Alegre, São Paulo e Recife, entre os anos de 2003 e 2006, 56\% a $70 \%$ dos entrevistados relataram ter sofrido discriminação em razão de sua sexualidade; e no que diz respeito às experiências de agressões foram apontados dados significativos com índices entre 58\% a 65\% nas quatro edições da pesquisa (FACHINNI \& SIMÕES, 2009). Agressões a homossexuais não são fatos novos ou isolados. Há vários anos o Grupo Gay da Bahia (GGB) alerta quanto a esta questão e expõe tristes e significativas estatísticas das 
mais variadas ordens contra gays brasileiros, de norte a sul do país. João Silvério Trevisan já destacava, em seu clássico "Devassos no Paraíso", inúmeros casos de violência e assassinatos divulgados especialmente a partir da década de 1980. Ao refletir sobre a sofisticação das ações destaca que:

(...) outro elemento em comum em quase todos é o grau de violência, tão exagerada que chega a parecer gratuita. (...) No final da década de 1980 e início dos 90, os assassinatos contra homossexuais se multiplicaram assustadoramente nas maiores cidades do país. Na verdade, tais 'crimes de ódio' podiam inserir-se num clima geral de pânico da Aids, que atingiu seu pico nesse período (TREVISAN, 2004, p.401).

As relações de gênero e de sexualidade também interferem e dialogam com o ambiente da cena e, sobretudo, no exercício da docência. Alguns bailarinos destacaram que o lugar do professor impõe um respeito maior no meio social em relação à função e/ou profissão de bailarino. Além disso, o fato de ser um professor homem, na dança, acaba atraindo as meninas e, sobretudo, os meninos, que buscam uma identificação e maior aproximação e afinidade. Abaixo, alguns informantes destacam e ratificam esta questão.

Então o professor começou a tomar conta, e a gostar de ser professor, mas o bailarino muito presente, até porque ajuda, o bailarino e o aluno também está na cena, você é o espelho do aluno, esse diálogo está muito fluente, as pessoas sabiam que eu era bailarino e dava aula (M.N. 53 anos).

Nas escolas, as professoras me adoram, dizem que eu tenho jeito com os alunos, principalmente com os meninos, de fazêlos dançar. Por ser homem eu atraio eles para a dança. Com ele os meninos dançam, elas falam! Um menino me disse que não gostava de dança e que por minha causa ele mudou e gostou de dança (C. 40 anos).

Muitos artistas, além de atuarem como bailarinos também exercem a função de professores em contextos outros, seja com crianças, adultos e/ou projetos sociais. O exercício da cena artística divide o lugar com a preocupação de aprimorar sua qualificação profissional. A questão do mercado de trabalho 
foi recorrente nas falas dos bailarinos que, cada vez mais, buscam aprofundar seus estudos na área da Dança. O contexto de Salvador, por meio da Universidade Federal da Bahia e seus Programas de Pós-graduação em Dança e Artes Cênicas, contribuíram decisivamente para este trânsito entre vida artística e vida acadêmica. Definitivamente, viver de/com Arte em Salvador é bem mais significativo do que em outras regiões do Brasil.

Voltei da Alemanha e entrei imediatamente aqui no Balé do Teatro Castro Alves como bailarino, por contrato temporário, depois fiz o último concurso. E ao mesmo tempo, em 1994, passei no concurso para professor na Escola de Dança da UFBA, mas em 1997 eu tive que fazer uma escolha e optei pela UFBA, visando uma carreira com maiores possibilidades. Fiz mestrado nas Artes Cênicas e o Doutorado em Educação, tudo aqui na UFBA (A. 53 anos).

Eu já tinha essa consciência, pensando nisso, eu escolhi a Licenciatura. Dancei em vários grupos, sempre dançando. Dei aula na própria Cia, a diretora tinha essa segurança em mim. Depois na Universidade, de cenografia, estudo do movimento para Educação Física, como substituto, e contrato em escolar particulares. Sempre atuei como professor, usando a criatividade do artista como fio condutor da pedagogia, por ser contemporâneo, eu sempre busco isso. Demanda temática é que traz a demanda técnica (C. 40 anos).

Sempre dei aula, durante todo o percurso como bailarino, daí a gente entra num círculo vicioso de dar aula pra complementar a renda. Eu sempre me cobrei muito, eu não procurei, as pessoas me chamavam para dar aula e eu sempre tratei com muito carinho esse lado de professor. E daí hoje eu queria fazer o mestrado, mas não me sinto tão preparado ainda, então estou cursando Licenciatura em Teatro para direcionar um bem maior de organizar essa experiência de corpo nas artes visando uma metodologia de ensino para a dança, no corpo cênico (T. 41 anos).

Compreendi, portanto, que o lugar e a função do professor, foram sendo construídos paralelamente à atuação como bailarino. Apesar de alguns seguirem a carreira, principalmente atuando na cena, muito deles investiram e seguiram estudando para se atualizar e aperfeiçoar como professores de dança. Dois professores de Danças de Afro, de Matriz Africana, atualmente são 
referência no cenário da Dança para além do contexto de Salvador. Além de suas rotineiras aulas, em mais de um local, seguidamente são procurados para proferirem palestras, seminários e para atuar na formação de outros estudantes de dança e até mesmo de outras áreas como Pedagogia, Educação Física e Teatro.

\section{ENVELHECENDO NA DANÇA}

Tradicionalmente a área da Geriatria, especialidade da Medicina, por meio do discurso da Saúde consolidou-se por orientações e tratamentos de enfermidades e tudo àquilo que se relacionava ao estudo da velhice, exclusivamente com a ênfase no tratamento de uma doença. Atualmente, a área da Gerontologia, cujo enfoque centra-se no processo histórico-social do envelhecer e não especificamente nas patologias senis, ampliou o olhar sobre os idosos e suas relações com as demais gerações, a partir de orientações psicológicas, sociológicas e antropológicas. Tais compreensões contrariam visões lineares e unidimensionais sobre o significado do tempo e das mudanças evolutivas (NERI, 2001). Estes "saberes gerontológicos" situam-se dentro de uma área científica que se diz interdisciplinar, denominada Gerontologia (DOLL, 2004).

As características da cena contemporânea apontadas por Edvaldo Couto (2007) denotam para um processo de ressignificação do culto ao corpo onde cada vez mais identidades híbridas e ambíguas reforçam a fluidez e a transitoriedade da carne. A condição espetacular do corpo associa-se ao desejo de modificá-lo quando as novas (bio)tecnologias ditam, para além de modismos, uma verdadeira cultura onde aparência, juventude e vigor estão cada vez mais disseminados. Como destaca o referido autor

Tornou-se urgente eliminar toda e qualquer insatisfação física e mental, acabar com uma real ou suposta imperfeição, corrigir cada detalhe (...) manter o vigor da juventude, exibir a aparência mais saudável, festejar a beleza conquistada com ajuda dos avanços tecnológicos e científicos: regimes, terapias, cosméticos, cirurgias, uso de próteses, novos medicamentos, manipulação genética. O culto ao corpo se tornou um estilo de vida, 
mas uma vida tecnocientífica. A promessa fascinante de um ganho suplementar de saúde, juventude e beleza conquistou um espaço inédito nos meios científicos e artísticos, na mídia, em todas as esferas do nosso cotidiano (COUTO, 2007, p.42).

A velhice é de certa forma negada e, em alguns casos, até combatida. Parecer/ficar velho ou velha, "naturalmente", é cada vez mais raro na contemporaneidade. Guita Debert (1999) ao focar a questão da (re)construção da velhice hoje, chama atenção para a heterogeneidade do envelhecimento e suas várias configurações e arranjos sociais. A autora destaca uma característica denominada de "dupla vulnerabilidade" ao relacionar idosos e as chamadas minorias, entre elas, os idosos negros, os de classe baixa e ainda os idosos "muito idosos", isto é, a partir de oitenta anos de idade.

Na medida em que fui me aproximando dos estudos de Gênero e Sexualidade e, sobretudo, do recorte investigativo acerca das Masculinidades, aliado a uma quase ausência de bibliografias, em língua portuguesa, que contemplassem o processo de envelhecimento de gays e lésbicas, percebi que:

(...) essa revisão aponta para várias lacunas dentro da literatura, há muito poucos esboços de pesquisas qualitativas e muitas populações ausentes nas pesquisas, incluindo deficientes, homossexuais, culturas diversas e aqueles menos saudáveis (GARDNER, 2006, p 77).

Neste sentido, a temática da velhice e o processo de envelhecimento ainda são pouco explorados no estudo das homossexualidades, sobretudo a masculina, principalmente em publicações nacionais. Só recentemente alguns grupos e seminários temáticos em congressos passaram a investir no tema a partir da década de noventa. Antônio Cristian Paiva ao refletir sobre esta questão destaca que se poderia

(...) apontar as lacunas nos estudos sobre geração e sexualidade e, num grau mais elevado ainda de dissociação, nos estudos sobre geração e sexualidades periféricas, as quais divergem do ideal normativo da matriz heterossexual, familista por definição (...) Se consultarmos as estudos sobre velhice no 
Brasil, verificaremos, como regra geral, o silêncio a respeito do envelhecimento homossexual (PAIVA, 2009, p.199).

Na coletânea de textos "Sexualidade e Saberes: convenções e fronteiras", organizado por Sergio Carrara (2004), Julio Simões contribui especificamente com esta temática ao relacionar a homossexualidade masculina e o paradigma do Curso da Vida (life course) abordando as representações do processo do envelhecimento homossexual masculino. Ao referir-se às concepções tradicionais acerca da velhice ocidental e aos valores disseminados na cultura de consumo contemporânea, o que ainda prevalece é a associação com a morte, o declínio, a finitude, perdas e depressão, ou seja, tudo àquilo que se vincula à concepção de corpo predominantemente biológica e produtiva.

O quadro complexifica-se ainda mais quando o envelhecimento homossexual masculino apresenta como pano de fundo os centros urbanos e as metrópoles, onde na chamada "cultura gay masculina" impera o interesse da beleza e juventude dos atributos físicos, da moda e de um mercado sexual hierarquizado (SIMÕES, 2004). Este autor reflete ainda sobre o aparecimento do que chama de "envelhecimento precoce" atribuído aos gays na faixa dos 30 a 40 anos de idade onde começam a enfrentar e a sofrer a crise do envelhecimento.

Soma-se a isto a solidão, o isolamento e até mesmo quadros depressivos, uma vez que a grande maioria dos gays não constituiu "família" e filhos para se preocupar e "preencher" seu tempo e retardar, em alguma medida, as preocupações com os efeitos do envelhecimento. As representações poderiam oscilar desde a imagem da "tia velha e meio gagá" ao "velho tarado". Por outro lado Julio Simões apresenta evidências do chamado envelhecimento bemsucedido, onde o nível de satisfação e qualidade de vida é melhor do que as gerações mais jovens. Em suas palavras:

Uma pesquisa sobre experiência e representações de maturidade e envelhecimento entre homens que fazem sexo com outros homens deveria, então, situá-las no cruzamento tenso e móvel entre as velhas e novas convenções sobre periodização 
da vida, envelhecimento e velhice e suas relações com a sexualidade e homossexualidade. Isso significaria levar em conta, numa frase, os arranjos, combinações, variações e passagens possíveis entre a tia velha deprimida e solitária e o coroa bemdisposto e bem acompanhado (SIMÕES, 2004, p. 421).

Preocupações sobre estar e/ou ficar sozinho, o medo da solidão, a ausência da visibilidade acerca de uma velhice feliz, a valorização da cultura da beleza e da juventude e a falta de uma preparação para a velhice foram alguns relatos de uma pesquisa sobre o processo de envelhecimento gay. Nas palavras do autor algumas reflexões acerca da temática.

Quando é, por exemplo, que um gay começa a envelhecer? Quando se depara em 'envelhescência'? Aos trinta? Aos quarenta? Aos cinquenta? A matriz heterossexual nesse sentido ajuda a delimitar um campo mais ou menos desenhado para essa marcação: envelhece-se quando os filhos saem de casa, ou quando casam, ou quando vêm os netos... Mas quando não há esses marcadores geracionais expressos na norma conjugal e familiar, quando é que se começa a envelhecer? $\mathrm{E}$ o que a experiência de envelhecer faz mudar a percepção de si, do outro e do mundo? (PAIVA, 2009, p.201).

$\mathrm{Na}$ área de Dança, diferentemente das outras artes onde o corpo é o próprio sujeito-objeto cênico, encarnado, ou seja, a própria obra artística, a fisicalidade e a manutenção corporal em manter-se dentro de certos padrões de beleza e saúde são perseguidas ao extremo.

Quando chega nos redondos, a gente para e pensa, trinta, quarenta, querendo ou não, marca uma fase da vida, uma década, uma vitória a mais. Pra mim funcionou mais em percepção às lesões mesmo, da minha última crise na lombar, eu já recomecei a repensar, eu já tinha trinta $A$ questão da recuperação demora mais (L. 37 anos).

Eu fui percebendo essa transição desse corpo, dos trinta aos quarenta é um período muito bom, de muito vigor, isso é bom, agora dos quarenta para os cinquenta é onde vem o peso do físico (M. N. 53 anos). 
Além da rotina das aulas regulares vários bailarinos acabaram buscando outras técnicas de movimento e de dança por conta própria a fim de aprimorar e complementar a manutenção do trabalho corporal na dança. Alguns deles buscam, também, desenvolver um trabalho próprio e diferenciado de preparação física na dança de modo a evitar lesões e manter-se, qualitativamente, por mais tempo na cena.

Na última montagem do Balé do Teatro Castro Alves, foi difícil pra mim, eu tenho um medo desse balé, porque exige muito de mim, muita energia quando acaba o espetáculo, então eu penso nos meus quarenta e um anos (T. G. 41 anos).

Depois foi butô, yoga, daí fui buscar fora pra mim, Klauss Vianna passou por aqui, essas figuras foram ótimas, abre uma porta pra entender o que eu estou procurando. Também fazer a sociedade entender isso, o bailarino amadurece ele entra em outro mundo, se reinicia um outro mundo. Comecei a me preocupar acho que foi por volta dos 40, foi na época que 35 anos já era velho (P. F. 57 anos).

E a relação com o futuro? E com a finitude? Todos os artistas investigados, sejam os bailarinos, sejam os professores, destacaram a ideia de que não é possível se afastar do universo da Dança. De alguma maneira, quando não puderem ou quiserem mais estar em cena, a atuação em outras ações do universo artístico poderá mostrar-se um caminho produtivo e prazeroso como coreógrafo, produtor, diretor, professor inclusive. Todas elas, no entanto, ligadas à dança.

Isso não passa pela minha cabeça mesmo se eu não estar na cena, eu vou estar envolvido. Acho que só vou parar quando eu der o último suspiro. Ou estudando, dando aula, ou em eventos, os nos Blocos afro, sempre ligado à dança, ela dança vai estar dentro de mim de alguma forma. Ser artista é para sempre, não existe isso de parar ou sair, é uma posição no mundo, de ser diferente. Eu vou continuar aberto a possibilidades, não fecho nada, quero continuar aprendendo (A.G. 45 anos).

A maioria dos bailarinos aqui são de quarenta a sessenta anos. Aqui podemos pesquisar, dançar, atuar na produção, dar aulas, coreografar. Agora estamos atuando em diferentes projetos 
com videodança: misoginia, LGBTfobia, racismo, uma dança mais politizada com o social, com o tempo de hoje (M.N. 53 anos).

Eu estou com cinquenta e sete anos, não me sinto velho, só vou parar quando Deus quiser, eu não me troco por nenhum jovem em cena, eles podem ganhar no músculo, mas em cena, na experiência não. Isso está encarnado. O pior de tudo eu acho que são as pessoas que ficaram velhas e querem que você fique velho também, só porque pararam querem que eu pare também (A. X. 57 anos).

Embora saibamos do período difícil e complexo que se configurou no Brasil atualmente, especialmente a área das Artes e da Educação, a partir de uma crise não somente financeira, mas, sobretudo, política, o contexto de Salvador/BA, se comparado ao restante do país, ainda guarda certa vantagem em relação à livre vivência e ao mercado de trabalho da dança. A historicidade e a força dos povos de matriz africana com suas danças e lutas continuam a influenciar as novas gerações, seja na cena artística, seja no exercício da docência. O grande circuito comercial do Carnaval de Salvador, as coreografias de artistas famosos, o roteiro de importantes shows nacionais e internacionais movimenta não somente o turismo de uma maneira geral, mas acaba fortalecendo o sonho de crianças e jovens de se tornarem dançarinos, bailarinos profissionais. Artistas da cena.

O universo acadêmico por meio da Universidade Federal da Bahia e seus Programas de Pós-graduação em Dança e em Artes Cênicas cumprem um papel relevante na formação de artistas em todo o Brasil. É recorrente a influência de artistas da Cena, de outros países, que participam de importantes eventos na área da Dança em Salvador.

\section{CONSIDERAÇÕES FINAIS}

Ao finalizar este texto, ficaram evidentes as influências das especificidades sociais e culturais do contexto de Salvador, primeira capital do país e local da primeira faculdade de Dança, na formação e na experiência dos bailari- 
nos investigados, seja na Escola de Dança da Fundação Cultural do Estado da Bahia (FUNCEB), seja no Balé do Teatro Castro Alves (BTCA). A vivência prática e artística da dança foi muitas vezes alimentada pelo olhar acadêmico de outros artistas e alunos do contexto universitário. A dança está presente e em movimento potente dentro e fora do contexto de ensino superior. Está nos terreiros de Candomblé, nas festas juninas, no Carnaval, nas Escolas, entre outros.

Outra característica relevante foi o fato recorrente do trânsito e do livre acesso a diversificadas técnicas de dança que o público masculino se beneficiou. Em Salvador, é comum o fato do mesmo bailarino fazer aulas de ballet clássico e capoeira, construindo um corpo potente, híbrido e diferenciado na dança. Ser homem auxiliou, abriu portas e multiplicou oportunidades na dança, seja na cena, seja na docência. Atrapalhou no sentido do preconceito familiar, este apontado como o mais forte e o maior desafio para quem escolheu viver de dança. Todos os artistas enfrentaram preconceito em relação à dança, desde o período escolar até a idade adulta no contexto social. A pesquisa apontou que quanto mais afeminado e "sensível" for a sua corporeidade a dança, maior será o preconceito a ser enfrentado. Nesse sentido, compreendo que a visibilidade gay é negociada, silenciada, adaptada por uma estratégia da própria sobrevivência.

Todos os bailarinos (sobre)vivem de sua arte. A maioria se desdobra em duas ou mais atividades, mesmo os bailarinos do Balé do Teatro Castro Alves, os quais não possuem dedicação exclusiva, atuam em outros trabalhos particulares de dança. Neste sentido, é praticamente impossível trabalhar com dança somente em um único lugar. Se por um lado o retorno financeiro é curto e processual, as possibilidades de trabalho ainda são múltiplas, abrangendo desde coreografias para festas juninas, blocos afro, videoclipes de artistas a projetos sociais. Compreendi que em relação ao preconceito e à docência, a função de professor impõe maior respeito em relação à profissão de bailarino. 
De acordo com meus informantes, o avanço da idade pode trazer a chamada maturidade cênica, a famosa "presença". A potência física e a virtuose passam a ficar em segundo plano. À medida que os bailarinos envelhecem, o virtuosismo perde a ênfase e a dramaturgia ganha a centralidade na cena. A fase dos trinta aos quarenta anos foi apontada como o período mais pleno e vigoroso da vida dos bailarinos. Enquanto que a fase que exige maiores adaptações, o enfrentamento de crises, rupturas e escolhas se deu no período que compreende dos quarenta aos cinquenta anos.

Muitos desses artistas não pensam em parar, em se aposentar da dança. Mesmo se não estiverem atuando como bailarinos, em cena, atividade de produção, coreografia e direção estão nos planos dos bailarinos. Novos projetos e desejos foram apontados por todos. Pesquisas individuais, temáticas, presença cênica e dramaturgia passam a ser o foco. Retomar os estudos ou iniciar uma faculdade também se mostraram caminhos possíveis para eles. Todos os artistas investigados se dizem privilegiados por morar e conviver em Salvador.

Assim, dentro do rico, complexo e plural contexto da primeira capital do Brasil, Salvador, esta pesquisa visibilizou um pequeno recorte das masculinidades dançantes na cena contemporânea. Meu objetivo não foi de fazer um levantamento histórico ou quantitativo acerca dos homens que dançam, mas, sim, relacionar a temática das masculinidades e suas relações com as questões de gênero e sexualidade(s) na cena contemporânea articulada ao processo do envelhecer. Também é preciso destacar que nem todos os bailarinos homens que fiz contato aceitaram participar da pesquisa, mostrando a complexidade e o quão delicado ainda é tratar sobre estas temáticas.

Neste sentido, faz-se necessário destacar que não trabalhei com uma fase específica da vida chamada de "velhice", após sessenta ou sessenta e cinco anos de idade mas, sim, com o próprio processo do envelhecer, ou seja, de que estamos todos envelhecendo dia após dia e que exatamente por isso precisamos refletir e propor algumas ações, possíveis, para manter ou apro- 
fundar a tão famosa qualidade de vida, sobretudo no campo das Artes, da inclusão e da Educação.

Dancemos! Envelheçamos!

\section{REFERÊNCIAS}

BORRILLO, D. A Homofobia. In: Homofobia \& Educação: um desafio ao silêncio.

LIONÇO, T.; DINIZ, D. (Orgs.) Brasília, Letras Livres: Ed. UnB, 2009.

BUTLER, J. Corpos que ainda importam. Dissidências de Gênero e Sexuais.

COLLING, L. (Org.) Salvador: EDUFBA, 2016.

CHASSOT, A. A Ciência é Masculina? São Leopoldo: Editora Unisinos - Coleção Aldus, 2003.

COUTO, E. Corpos Mutantes - Ensaios sobre novas (d)eficiências Corporais. Porto Alegre: Ed. da UFRGS, 2007.

DEBERT, G. G. A Construção e a Reconstrução da Velhice: Família, Classe Social e Etnicidade. In: Velhice e Sociedade. Campinas: Papirus, 1999.

DOLL, J. O campo interdisciplinar da gerontologia. In: Tempo de envelhecer: percursos e dimensões psicossociais. Rio de Janeiro: NAU, p. 83-108, 2004.

DUARTE, G.O. Masculinidades dançantes em Pelotas/RS. In: Paralelo 31, v. 2. Pelotas, p. 78-87, 2016.

FACCHINI, R; SIMÕES, J. A. Na trilha do Arco-íris: do Movimento Homossexual ao LGBT. São Paulo: Editora Fundação Perseu Abramo, 2009.

GARDNER, P. J. Envelhecimento saudável: uma revisão das pesquisas em Língua Inglesa. In: Revista Movimento, Porto Alegre, v.12, n. 02, p. 69-92, 2006.

GOELLNER, S. V. A produção cultural do corpo. In: LOURO, G. L.; NECKEL, J. F.; GOELLNER, S. V. (Orgs.). Corpo, gênero e sexualidade: um debate contemporâneo na educação. Petrópolis: Vozes, 2003.

HALL, S. Quem precisa de identidade? In: SILVA, T. T. (Org.) Identidade e diferença: a perspectiva dos estudos culturais. Petrópolis: Vozes, 2000.

LOURO, G. L. Gênero, Sexualidade e Educação: uma perspectiva pós-estruturalista. Petrópolis: Vozes, 1998.

MEYER, Dagmar E. Gênero e educação: teoria e política. In.: Corpo, Gênero e sexualidade - um debate contemporâneo na educação. Guacira L. Louro, Jane F. Neckel, Silvana V. Goellner (orgs.). Petrópolis, RJ: Vozes, 2003. 
MISKOLCI. R. Não somos, queremos. In: COLLING, L. (Org.) Stonewall 40 + o que no Brasil? Salvador: EDUFBA, 2010.

NERI, A. L. Paradigmas Contemporâneos sobre o Desenvolvimento Humano em Psicologia e em Sociologia. In: NERI, A. L. (Org.) Desenvolvimento e Envelhecimento - perspectivas biológicas, psicológicas e sociológicas. Campinas: Papirus, 2001.

PAIVA, A. C. S. Corpos/Seres que não importam - Sobre homossexuais velhos. Bagoas: Revista de Estudos Gays. UFRN, v.3. p. 191-208, 2009.

SCOTT, J. Gênero: uma Categoria útil de Análise Histórica. In: Revista Educação e Realidade, Porto Alegre, v.2, n.2, p. 71-99, 1995.

SEFFNER, F. Composições (com) e resistências (à) norma: pensando corpo, saúde, políticas e direitos LGBT. In: COLLING, L. (Org.) Stonewall $40+0$ que no Brasil?. Salvador: EDUFBA, 2011.

SIMÕES, J. A. Homossexualidade masculina e Curso da Vida: pensando idades e identidades sexuais. In: CARRARA, S. et al (org.) Sexualidade e Saberes: Convenções e Fronteiras. Rio de Janeiro: Garamond, 2004.

SPARGO, T. Foucault e a Teoria Queer: seguido de Ágape e Êxtase; orientações pós-seculares. Belo Horizonte: Autêntica, 2017.

TREVISAN, J. S. Devassos no paraíso: a homossexualidade no Brasil: da colônia à atualidade. 6. ed. Rio de Janeiro: Record, 2004.

Recebido em 16 de abril de 2018 Aprovado em 29 de junho de 2019 